\title{
Human Anti-Mouse Antibodies Positive
}

National Cancer Institute

\section{Source}

National Cancer Institute. Human Anti-Mouse Antibodies Positive. NCI Thesaurus. Code C139787.

Indicates that human anti-mouse antibodies have been detected in a sample. 